\title{
Developing Financial Literacy in Budding Entrepreneurs
}

\author{
Thomas O'Neal and Dennis Kulonda \\ University of Central Florida
}

\begin{abstract}
Most engineering curricula devote little time to the development of financial literacy among engineering students. Many civil and industrial engineers obtain some exposure in an undergraduate engineering economics course; but these courses generally focus primarily on the time value of money and the comparison of alternatives based upon discounted cash flow. Even the ubiquitous topic of taxes on income is deferred until late in the course.

Resolving this dilemma, short of enrolling in Accounting 101, appears to be difficult at best. Fortunately, there are materials which can convey the concepts required to understanding accounting principles, processes and underlying concepts at a level that will enable engineers to work productively with the bankers, investors and accountants who will play a huge role in any new venture. These materials can accomplish that in a finite numbers of class sessions through the use of case materials. Cases based upon an entrepreneurial scenario both motivate and energize class discussions. This paper will review the materials available to develop financial literacy and explain their use in a three-session module which could be included in an entrepreneurship course or a senior design course The presentation will focus on the use of a specific case to convey the essentials of accrual accounting to a novice audience.
\end{abstract}

\section{Introduction}

Teaching financial accounting to engineering managers is a contentious proposition. Those who argue for this content view the material as important and essential in providing a business perspective for engineering students. Those who argue against including accounting courses in the curriculum usually are reluctant to sacrifice the space in the curriculum because of the rapid expansion of technical material in the engineering disciplines. Both arguments have merits and some compromise is needed. Certainly it is difficult to justify the usual two-course sequence of financial and managerial accounting usually required in the business school curricula. Even the single combined course offered in some business schools seems too a large price to pay according to many engineering faculty. Since the students usually find the accounting material uninteresting and in their view, unimportant, they tend to side with the latter faculty group creating even more impetus for the technology driven argument, i.e., avoid the topic altogether. 
Of course, this is a narrow argument which, if followed, graduates engineering students bereft of any financial literacy and unable to understand the accounting scorecard in their new venture. One possible solution is to identify the most critical learning objectives and deliver them as a portion of a business-flavored course in engineering. One such opportunity lies in the engineering economics course. The purpose of this paper is to suggest an approach to an instructional module in accounting that meets critical knowledge needs, generates engineering student interest and motivation, and fits within a reasonable time frame.

\section{Identifying Critical Knowledge}

A model developed and used by the author and colleagues in course development is based upon the work of Mager ${ }^{1}$ regarding learning objectives. The extension to Mager's work involves a Levels of Learning model that sorts learning objectives into three categories: Awareness, Understanding, Capability (A,U,C). These categories are meaningful if they are referenced to a specific performance objective. In this case the performance objective is ability to use accounting information in making decisions that affect the financial condition of the firm. This includes reading and interpreting financial reports, understanding the accounting framework for accrual accounting, and knowing the standards and conventions underlying the development of accounting reports.

The Capability level is the most exacting of the three levels. However, we are not concerned with the capability to generate accounting information per se. The learning objectives addressed here are targeted to the ability to read and interpret accounting information for basic and straightforward circumstances. Because business school accounting classes are targeted to the Capability Level for the generation of financial statements, the class time for attainment of their learning objectives is much longer than necessary for engineers. Engineers, however, can achieve the performance level by focusing on the second level, Understanding. This does not obviate their need to work through semi-realistic situations and generate basic financial reports as a way of developing and confirming their understanding of the accounting concepts that they must learn. It does however eliminate the need for extensive drills that really are teaching bookkeeping rather than accounting concepts. That difference in focus provides the avenue for developing a set of specific learning objectives that can be met in a fraction of a semester.

\section{A Survey Based On the AUC Model}

In order to develop a solid understanding of the topics and the attendant learning objectives appropriate for budding entrepreneurs, a survey of qualified professionals was developed and reported in a prior paper. ${ }^{2}$ This survey was based on the AUC model and asked respondents to indicate, on a scale of 1-5, the depth of understanding needed for a new entrepreneur for each topic in a set of accounting related topics. It also asked each 
qualified respondent to rate the observed skill levels in novice entrepreneurs on the same scale. Responses to the first question indicate the criticality of the topic. The difference between the two responses on a specific topic measure the size of the knowledge gap. Thus, learning objectives could be developed for each topic based upon closing the gap on critical items

The survey respondents are drawn from incubators in Florida including those in Central Florida and others. They include Incubator Managers, Small Business Advisors, Commercialization Officers and other who have significant exposure to technological entrepreneurs. Since the survey instrument is somewhat complex, it was administered face to face wherever possible.

Preliminary results indicate that an understanding of accrual accounting concepts is essential. New entrepreneurs must be able to present and discuss with bankers and venture capitalists income statement, balance sheets and other documents based upon accrual accounting principles.

\section{Attaining the Accounting Understanding}

One benchmark for the attainment of financial literacy is the popular monograph produced by Merrill Lynch, $\underline{\text { How to Read A Financial Report }}{ }^{3}$. It is available free of charge from Merrill Lynch. Its intent, of course, is to educate potential customers of the investment service and it assumes no prior background in accounting. Its glossary of terms provides a useful guide for the breadth of education required for financial literacy. However, the depth of the required understanding must go beyond glossary definitions. If engineers are to communicate with managers in their company, it is essential that they understand the logic and structure of the accrual accounting process that generates the reported numbers. The brochure takes the viewpoint of the potential investor and does not cover accounting concepts or the assumptions and accounting principles behind the numbers reported in financial statements.

An alternative learning aid is the note, Primary Financial Statements ${ }^{4}$, available from Harvard Business School Publishing. It explains the basic income and financial statements and includes a six-page appendix that carefully explains accounting transactions, closing the books, and statement construction. The first 20 pages explain the accounting concepts and the rationale for the various categories of accounts. Although well written, it requires patience for engineers as it is predictably dry and matter of fact in its exposition. The most natural follow up piece, Assessing a Company's Future Financial Health ${ }^{5}$ is more interesting for the students. It is presented in programmed learning context, making it a good exercise for out-of-class preparation. It also includes a short case, The Case of the Unidentified Industries, which requires students to match companies (automotive, electric utility, grocery chain, aerospace, and importer) to five sets of financial statistics. This helps drive home the notion that there 
are no absolutes, each company's ratios must fit the characteristics of their business and must be compared with like companies.

An alternative to these materials is a financial accounting tutorial developed for engineering students at Stevens Institute in New Jersey ${ }^{6}$. It includes seven sessions which cover the gamut of accounting basics and logic through financial statement analysis and comparative ratios. It should generate learning interest as it is interactive but it focuses upon "how to do it", with little emphasis on "why we do it".

A more comprehensive way to communicate accounting concepts and why they are important can be developed through the Chemalite $^{7}$ case. There, students observe the first and second board meetings of an entrepreneurial start-up, Chemalite. They observe the first period's results and must resolve a dispute among board members regarding the first period's profit (or lack thereof). They are led to understand the need for accrual accounting, and the difference between capitalizing and expensing an outlay of cash.

Armed with this newly found knowledge of accounting based upon common sense and a set of standard conventions and accounting principles, students are required to take on the task of developing the financial scorecard for the second accounting period. In so doing they are shown, quite vividly, the difference between cash accounting and accrual accounting and are led to the need for statements of cash flow as the third major accounting report.

Using the Materials

As may be obvious these are highly interactive sessions where students must prepare ahead of class and learn much of the major lessons by discovery. If this seems heartless, consider the alternative of lecturing this deadly, dull material. For example, the Chemalite case is designed to be taught before any coverage of bookkeeping, debits, credit, T-accounts, etc. This will allow the class to focus on the important concepts before attempting to cope with an unfamiliar structure.

In the first session, students read about a partnership among an entrepreneur with a patent and three partners who contribute $\$ 125,000$ each for a one quarter share of the enterprise. After some expenditures on legal fees, manufacturing equipment and raw materials, six months have elapsed and the first state of the company meeting is in session. Arguments among the partners regarding how to assess the progress ensue and students are asked to settle the arguments by developing income statements and a means to account for the investment in assets. In so doing students are forced to grapple with the valuation of the patent, financial statements, use of historical costs, etc in assessing the progress. They are led to understand why these tools have been necessary rather than how to construct them. As the few simple transactions are discussed, the principles of accounting (See Appendix) are raised and used to illustrate both the conflicts and usual decisions in gray areas such as "capitalizing" or "expensing" cash outlays. With this simple exercise, 
students can see application of nearly all of the standard principles. More importantly, they are led to understand how the rules of accounting provide useful information.

After reconciling the first six months of operation, an accounting exercise such as the one developed in Primary Financial Statements, or one available from the authors, covers accounting basics at the level needed to complete the second half of the assignment. There, students determine the impact of the second six months worth of activity. They create an income statement, balance sheet and cash flow statement to summarize the impact. In so doing they learn the rationale behind the choices of how to account for each event. Accounting concepts listed in the Appendix, most importantly, revenue recognition, matching, conservatism, materiality, depreciation, etc. are brought to life as essential to resolving the issues. By focusing on the objective of de-mystifying accounting, student confidence can be greatly enhanced.

A third session reinforces this constructively. Students can easily prepare the programmed learning document, Assessing a Company's Future Financial Health and profit from discussing it and its enclosed mini-case, The Case of the Unidentified Industries. The three-session program for accomplishing the instruction appears in Table I below.

Table I The Proposed Three Session Structure

\begin{tabular}{|c|c|c|c|}
\hline Session & Class Activities & Learning Objectives & $\begin{array}{l}\text { Prior Student } \\
\text { Preparation }\end{array}$ \\
\hline 1 & $\begin{array}{l}\text { Read Chemlite First six months } \\
\text { Discuss Alternative Solutions } \\
\text { Walk through Climax example } \\
\text { in Primary Financial } \\
\text { Statements }\end{array}$ & $\begin{array}{l}\text { Understand why accrual } \\
\text { accounting is necessary. } \\
\text { Learn concepts of } \\
\text { capitalization, motivation } \\
\text { for accounting principles, } \\
\text { balance sheet identity, }\end{array}$ & None \\
\hline 2 & $\begin{array}{l}\text { Discuss alternative solutions to } \\
\text { second half of Chemlite }\end{array}$ & $\begin{array}{l}\text { Reinforcement of } \\
\text { accounting concepts. } \\
\text { Practice accounting } \\
\text { transactions }\end{array}$ & $\begin{array}{l}\text { Read Primary Financial } \\
\text { Statements } \\
\text { Read and prepare second } \\
\text { six months of Chemlite }\end{array}$ \\
\hline \multirow[t]{2}{*}{3} & $\begin{array}{l}\text { Review solutions for financial } \\
\text { health. }\end{array}$ & $\begin{array}{l}\text { See the mechanics of the } \\
\text { ratios. Understand the } \\
\text { logic for each and the } \\
\text { rationale for the numerator } \\
\text { and denominator. }\end{array}$ & $\begin{array}{l}\text { Prepare Assessing a } \\
\text { Company's Future } \\
\underline{\text { Financial Health }}\end{array}$ \\
\hline & Discuss Unidentified Industries & $\begin{array}{l}\text { Understand how } \\
\text { companies differ }\end{array}$ & $\begin{array}{l}\text { Prepare The Case of the } \\
\text { Unidentified Industries }\end{array}$ \\
\hline
\end{tabular}




\section{Conclusion}

New entrepreneurs must have an understanding of accrual accounting and how its rules and conventions affect the way in which their business is portrayed to others. Experienced professionals believe that an understanding of these elements is essential. Fortunately, there is standalone material available that helps students focus on the concepts rather than the mechanics of accounting. Because these require only three 75 minute sessions to convey well, they can be inserted into an existing course like engineering economics, packaged with other materials in an entrepreneurship seminar, or offered as a short course in a not for credit setting. Whichever path, the journey is well worth the effort. Financial literacy is essential to business success.

\section{ACNOWLEDGMENT}

This research was supported by a grant from the National Science Foundation

\section{BIBLIOGRAPHY}

1 Mager Robert F., Preparing Instructional Objectives, Fearon Publishers, 1962

${ }^{2}$ Preparing Tomorrow's Entrepreneur: What Must Engineers Know About Finance?, Kulonda, Dennis and Tom O’Neal ASEE Southeast Proceedings, April 2004

${ }^{3}$ Merrill Lynch, How to Read A Financial Report

4 Primary Financial Statements, Harvard Business School Publishing, 9-197-178

5 Assessing a Company's Future Financial Health, Harvard Business School Publishing, 9-201-177

${ }^{6}$ Evaluating the Effectiveness of Computer Tutorials Versus Traditional Learning, Journal of Engineering Education, Merino, Donald and Abel, Kate, Vol.92, No.2, April 2003

${ }^{7}$ Chemalite, Inc. Harvard Business School Publishing, 9-177-078

8 Excerpted with permission from Capital Investment Analysis for Engineering and Management, Third Edition, Canada, Sullivan, Kulonda and White, Prentice-Hall ,forthcoming 2005.

THOMAS O'NEAL is Director of Research at the University of Central Florida. In that role, he directs the operation of the UCF Technology Incubator, perennially ranked among the top incubators in the country. He has served as business development manager for several entrepreneurial ventures and has UCF degress in electrical engineering, business administration and engineering management. He is currently a doctoral candidate in Engineering Management at UCF

DENNIS J. KULONDA is Associate Professor of Management at the University of Central Florida. His research and teaching is focused in Engineering Management. He has extensive experience in the development and management of industrial engineering projects in operational and financial planning and is developing a third edition of Capital Investment Analysis for Engineering and Management with Professors Canada, Sullivan and White. 


\section{Appendix Accounting Principles ${ }^{8}$}

Business Entity - Financial Statements are developed for a business separate from its owners. What occurs in its owner's affairs is not considered. Personal assets of owners are not co-mingled with those of the business, as this would distort measurement of the business

Going Concern - Accounting statements for a business entity assume that the entity is a going concern that will continue operations into the foreseeable future unless specifically stated otherwise. For example, accountants assume inventory is saleable in the future and hence value it at its manufacturing cost unless there are specific reasons to believe that it deteriorates or will become obsolete.

Monetary Measurement- Accounting measures only those transactions that have a monetary value. Note that there may be many very important factors which have value that are not considered in the accounting system; e.g. a talented workforce, a new revolutionary product or an effective lobbyist all can create extraordinary opportunities. But their value to the organization is not reflected in the accounting records unless there is a verifiable financial transaction tied to their services.

Accounting Period-Accounting statements reflect activity during or at the end of a standard time window, called the accounting period. Publicly held companies are required to report quarterly and annually-- most often, but not always, matching the calendar year.

Historical Cost-Business transactions are valued at the validated transaction cost or price at the point in time when the transaction occurred. Subsequent changes in market prices of assets are not normally recorded in the accounting statements; hence, the value of an enterprise is often different than its book value (the sum of the historical values of all its assets after allowance for depreciation).

Realization- Revenue is realized in the accounting system whenever some standard objective indication of a sales transaction occurs. Often this occurs at the point of shipping, or at the point of invoicing. Exceptions to the delivery convention occur. For example companies performing long term projects often invoice progress payments to their customers

Matching Costs and Revenues- This important concept mandates the matching of revenues with the costs of resources consumed in providing the goods and services that generated the revenue. This is the basis for the accounting definition of profit or net income. It may require that some revenues be deferred to the future. For example, the revenue received for a three year magazine subscription may be held as an asset called "deferred income" until it is earned year by year 
and matched with the expenses of producing and delivering the magazine. Similarly, expense recognition may be delayed until intended revenues materialize. This is the case when raw materials are purchased for resale but held in inventory until a sales occurs. The purchased lot of raw materials are said to be "capitalized", meaning that they are held as an asset. The amount used in subsequent sales are said to be "expensed", meaning that the asset has been sold and its value must be netted against the revenue earned to contribute toward the profit for the accounting period.

Consistency-requires that the transaction processing conventions adopted to conform to accounting principles remain consistent from year-to-year. Auditors are required to certify that accounting statements have been prepared "on a basis consistent with that of the preceding year". When changes are made to accounting policies and practices these should be disclosed in the annual reports as an "accounting change".

Disclosure- accounting reports must disclose enough so that they will not mislead careful readers. This disclosure can be made in the financial statements or in the notes to the statements

Conservatism- must be applied in deciding which of several alternative treatments should be applied to account for a specific transaction. This means that preference should be given to those treatments which understate asset values or overstate liabilities.

Materiality- Inconsequential transaction may be handled expediently. Material or significant transactions must conform to accounting standards 